\title{
Cognitive and motor shifting aptitude disorder in Parkinson's disease
}

\author{
AR COOLS,${ }^{*}$ JHL VAN DEN BERCKEN, $\dagger$ MWI HORSTINK, $\ddagger$ KPM VAN SPAENDONCK,, \\ HJC BERGER§ \\ From the Department of Pharmacology, ${ }^{*}$ Department of Special Education, $\dagger$ Department of Neurology $\ddagger$ and \\ Department of Medical Psychology, § University of Nijmegen, Nijmegen. The Netherlands.
}

SUMMARY Eighteen patients suffering from Parkinson's disease and nineteen control subjects, who were matched for age and intelligence, were compared in tests measuring "shifting aptitude" at cognitive and motor levels (word production, sorting blocks or animals, and finger pushing sequences). It was found that Parkinson patients produced fewer different names of animals and professions in one minute than control subjects, needed more trials for detecting a shift in a sorting criterion, and produced fewer finger responses in a change of pushing sequence than control subjects. These results are interpreted as reflecting a central programming deficit that manifests itself in verbal, figural and motor modalities, that is, a diminished "shifting aptitude" characteristic of patients with dysfunctioning basal ganglia. The results are discussed in relation to changes of behaviour organisations in animals with dysfunctioning basal ganglia.

For many years, the basal ganglia have been known to be involved in motor functioning. The basal ganglia are also believed to play a circumscribed role in programming ongoing behaviour. ${ }^{1-7}$ There is, also, belief that the basal ganglia play a definite role in cognitive functioning. ${ }^{8-13}$ (cf. refs $14-15$.) Of those notions the last two rely mainly on studies of Parkinson's disease, a progressive illness that is accompanied by neuropathology in the basal ganglia. However, the deficits in question may, or may not, be related to abnormal function of the basal ganglia, as the pathology of patients with Parkinson's disease is not restricted entirely to the basal ganglia. ${ }^{15}$ In order to resolve this question, data recently obtained on the basal ganglia of animals ${ }^{13618}$ were used to formulate the following hypotheses as to the sort of deficits in patients with dysfunctioning basal ganglia.

First, patients with abnormal function of the basal ganglia, for example Parkinsonian patients, should have a decreased ability to rearrange arbitrarily the serial order of the components of behavioural programmes. Following Bowen" who refers to "shifting

Address for reprint requests: Dr AR Cools, Dept of Pharmacology, University of Nijmegen, PO Box 9101, 6500 HB Nijmegen, The Netherlands.

Received 16 May 1983 and in revised form 20 October 1983 Accepted 18 November 1983 set", we use the term "shifting aptitude", being the ability to reorganise behaviour according to the requirements of the task. Accordingly, they should have a diminished "shifting aptitude" as to behaviour not directed by currently available sensory information. Concerning the characteristic features of Parkinson's disease deficits in motor control, there are already some indications that these patients have lost their ability to control "open loop" voluntary movements. ${ }^{19-22}$. The available information about their cognitive functioning is still controversial (see Discussion). Nevertheless, there is no doubt that Barbeau highlighted a crucial aspect by stating that Parkinson's disease patients are unable to shift to a new grouping if not prompted or guided..$^{14}$

Second, such a diminished "shifting aptitude" should manifest itself at distinct levels of cerebrally organised behaviour. Accordingly, it should manifest itself in tasks with varying degrees of complexity, varying from simple motor tasks on the one hand, to complex cognitive tests on the other.

Finally, manifestations of a diminished "shifting aptitude" at hierarchically less complex levels should always be accompanied by analogous manifestations at hierarchically more complex levels; the reverse should not be true. Indeed, there is already some evidence that increased task complexity produces a disproportional decrease in the performance 
Table 1 Subject profile of Parkinson patients

\begin{tabular}{|c|c|c|c|c|c|c|c|c|c|c|}
\hline \multirow{2}{*}{$\begin{array}{l}\text { Patient } \\
n r .\end{array}$} & \multirow{2}{*}{$\begin{array}{c}\text { Age } \\
(y r)\end{array}$} & \multirow{2}{*}{$\begin{array}{l}\text { Sex } \\
m, f\end{array}$} & \multicolumn{2}{|c|}{ Tremor } & \multicolumn{2}{|c|}{ Rigidity } & \multicolumn{2}{|c|}{ Akinesia } & \multirow{2}{*}{$\begin{array}{l}\text { Hoehn-Yahr } \\
\text { score }\end{array}$} & \multirow{2}{*}{$\begin{array}{l}\text { Dom. } \\
\text { hand }\end{array}$} \\
\hline & & & $R$ & $L$ & $\boldsymbol{R}$ & $L$ & $R$ & $L$ & & \\
\hline $\begin{array}{r}1 \\
2 \\
3 \\
4 \\
5 \\
6 \\
7 \\
8 \\
9 \\
10 \\
11 \\
12 \\
13 \\
14 \\
15 \\
16 \\
17 \\
18\end{array}$ & $\begin{array}{l}63 \\
66 \\
70 \\
69 \\
67 \\
71 \\
47 \\
50 \\
51 \\
59 \\
41 \\
47 \\
58 \\
70 \\
63 \\
67 \\
68 \\
64\end{array}$ & $\begin{array}{l}\mathbf{f} \\
\text { m } \\
\mathbf{f} \\
\mathbf{f} \\
\mathbf{f} \\
\mathbf{f} \\
\mathbf{m} \\
\mathbf{m} \\
\mathbf{f} \\
\mathbf{m} \\
\mathbf{f} \\
\mathbf{m} \\
\mathbf{m} \\
\mathbf{f} \\
\mathbf{f} \\
\mathbf{f} \\
\text { m } \\
\text { f }\end{array}$ & $\begin{array}{l}0 \\
1 \\
2 \\
2 \\
0 \\
2 \\
0 \\
0 \\
2 \\
1 \\
1 \\
0 \\
2 \\
1 \\
1 \\
0 \\
1 \\
0\end{array}$ & $\begin{array}{l}1 \\
1 \\
1 \\
0 \\
1 \\
1 \\
0 \\
0 \\
1 \\
1 \\
2 \\
1 \\
1 \\
1 \\
2 \\
3 \\
2 \\
0\end{array}$ & $\begin{array}{l}1 \\
1 \\
0 \\
2 \\
1 \\
1 \\
0 \\
1 \\
2 \\
2 \\
1 \\
1 \\
2 \\
2 \\
2 \\
1 \\
2 \\
1\end{array}$ & $\begin{array}{l}2 \\
1 \\
0 \\
1 \\
1 \\
1 \\
0 \\
1 \\
0 \\
2 \\
1 \\
1 \\
1 \\
1 \\
3 \\
2 \\
3 \\
1\end{array}$ & $\begin{array}{l}1 \\
2 \\
1 \\
2 \\
1 \\
1 \\
1 \\
1 \\
2 \\
2 \\
1 \\
2 \\
3 \\
2 \\
2 \\
1 \\
2 \\
1\end{array}$ & $\begin{array}{l}2 \\
2 \\
1 \\
1 \\
1 \\
1 \\
1 \\
1 \\
1 \\
2 \\
1 \\
2 \\
1 \\
2 \\
2 \\
2 \\
2 \\
1\end{array}$ & $\begin{array}{l}3 \\
3 \\
1 \\
2 \\
3 \\
2 \\
1 \\
2 \\
2 \\
2 \\
2 \\
3 \\
3 \\
3 \\
3 \\
2 \\
4 \\
1\end{array}$ & $\begin{array}{l}\mathbf{R} \\
\mathbf{R} \\
\mathbf{R} \\
\mathbf{R} \\
\mathbf{R} \\
\mathbf{R} \\
\mathbf{L} \\
\mathbf{R} \\
\mathbf{R} \\
\mathbf{L} \\
\mathbf{L} \\
\mathbf{R} \\
\mathbf{R} \\
\mathbf{R} \\
\mathbf{R} \\
\mathbf{R} \\
\mathbf{R} \\
\mathbf{R}\end{array}$ \\
\hline
\end{tabular}

of Parkinson's disease patients..$^{23-25}$

This paper reports results of studies dealing with these hypotheses and aims to provide evidence that Parkinson's disease patients indeed have a diminished shifting aptitude at the motor and cognitive level. Since the human data collected in this study are highly analogous to those found in animals with hypofunctioning basal ganglia (see Discussion), it is tentatively concluded that the basal ganglia of man are also involved in programming cognitive behaviour.

\section{Methods}

Subjects

The Parkinson group consisted of 18 patients selected on the basis of an unequivocal diagnosis of Parkinson's disease from 25 preselected Parkinsonians in the outpatients' Department of Neurology at the University of Nijmegen. Seven were male, and eleven were female. The mean age was 60.8 years $(S D=9 \cdot 3)$. Only patients who were in a clinically stable state for a minimal period of one month before the study were asked to co-operate (with informed consent). Medication was neither changed nor stopped during the investigation. The patients had not been submitted to stereotactic surgery. The diagnosis of Parkinson's disease was based on clinical assessment of the symptoms tremor, rigidity and akinesia. Parkinson's disease patients with non-Parkinsonism symptoms, EEG and CT scan abnormalities, symptoms of depression, cerebrovascular disease and presensile or senile dementia were excluded. Table 1 shows the subject profile for the Parkinson's disease patients. The symptom scores were evaluated by the

Table 2 Medication data for Parkinson patients

\begin{tabular}{|c|c|c|c|c|c|c|c|c|c|c|}
\hline \multirow{2}{*}{$\begin{array}{l}\text { Patient } \\
\text { nr. }\end{array}$} & \multirow{2}{*}{$\begin{array}{l}\text { Duration of } \\
P D(y r)\end{array}$} & \multicolumn{3}{|c|}{ Duration of medication } & \multicolumn{6}{|c|}{ Doses (mg/day) } \\
\hline & & $a$ & $b$ & $c$ & 1 & 2 & 3 & 4 & 5 & 6 \\
\hline 1 & $5 \cdot 5$ & 4.5 & 0.25 & - & & 1 & & & & 400 \\
\hline 2 & 3.0 & 2.5 & - & $2 \cdot 5$ & 150 & & & 200 & & \\
\hline 3 & 4.0 & - & - & - & & & & & & \\
\hline 4 & $1 \cdot 5$ & - & 0.25 & - & & & & & & 400 \\
\hline 5 & 4.5 & 2.5 & - & $2 \cdot 5$ & 150 & & & 300 & & \\
\hline 6 & 6.0 & 2.5 & 1.5 & - & & & & & & 400 \\
\hline 7 & $5 \cdot 0$ & $2 \cdot 5$ & - & - & 50 & & & & & \\
\hline 8 & 6.5 & $2 \cdot 5$ & $2 \cdot 0$ & - & & & & & & 300 \\
\hline 9 & 5.0 & $2 \cdot 5$ & - & - & 150 & & & & & \\
\hline 10 & 1.5 & 1.5 & 1.5 & $1 \cdot 5$ & 200 & & & 200 & & \\
\hline 11 & $5 \cdot 5$ & - & $\overline{5}$ & - & & & & & & \\
\hline 12 & $6 \cdot 5$ & $5 \cdot 5$ & $5 \cdot 5$ & - & & & & & 1600 & \\
\hline $\begin{array}{l}13 \\
14\end{array}$ & $\begin{array}{r}7 \cdot 5 \\
14 \cdot 5\end{array}$ & $\begin{array}{r}6 \cdot 5 \\
13 \cdot 0\end{array}$ & $\begin{array}{l}5.0 \\
6.0\end{array}$ & $6 \cdot 5$ & $\begin{array}{l}150 \\
300\end{array}$ & & & 200 & $\begin{array}{l}500 \\
3200\end{array}$ & 100 \\
\hline 15 & 5.0 & 130 & 3.0 & - & & & & & & 200 \\
\hline 16 & $4 \cdot 0$ & 3.5 & - & - & & 1 & & & & 200 \\
\hline 17 & $11 \cdot 5$ & 9.0 & 6.0 & - & 100 & & 4 & & 3500 & \\
\hline 18 & $7 \cdot 0$ & 6.0 & $5 \cdot 0$ & - & 150 & & & & & 600 \\
\hline
\end{tabular}

$\mathrm{a}=$ anticholinergics; $\mathrm{b}=$ dopa; $\mathrm{c}=$ amantadine

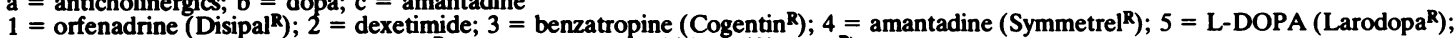
$6=$ L-DOPA + benserazide $\left(\right.$ Madopar $\left.^{\mathbb{R}}\right)$ or L-DOPA + carbidopa $\left(\right.$ Sinemet $\left.^{\mathbb{R}}\right)$ 
same neurologist ( $M$ Horstink) on the day of the investigation, at the end of the psychological and motor tests. The severity grade of arm and hand symptoms was scored on a four-point rating scale (absent, slight, moderate, strong) for tremor, rigidity and akinesia. The Hoehn-Yahr score was used as a measure for overall disability. ${ }^{26}$ Only a small number of symptoms are listed in table 1 . The patients listed there were receiving medication and, consequently, the table does not show the full clinical picture of the original diagnosis of Parkinson's disease. Data with respect to the pharmacotherapeutic treatment of the patients are given in table 2. The control group, which consisted of 19 subjects, had neither central neurological symptoms nor complaints concerning their arms and hands. Ten control subjects were male, and nine were female. The mean age of the control group was 60.0 years $(S D=11 \cdot 6)$. Whenever it was possible, the partners of the patients were invited to participate in the study.

\section{Tests}

"Shifting aptitude" in various modalities (verbal, figural and motor) was measured by using several criterion tests. If possible, existing tests were chosen, although several tests had to be redesigned because of the relatively long duration of the available ones. The Parkinson's disease patients and the control subjects were compared with respect to basic motor performance, intelligence (verbal and figural), short-term memory and attention by means of reference tests; the latter were also used to rule out general mental deterioration as an explanation for group differences in "shifting aptitude". In addition to the criterion and reference tests, the subjects completed a series of tests, the results of which will be presented elsewhere.

\section{Reference tests}

Five subtests of the Wechsler Adults Intelligence Scale ${ }^{27}$ were used to assess general mental deterioration: VOCABULARY and SIMILARITIES, measuring verbal intelligence; the score on the latter test markedly decreases with mental deterioration, whereas on the first test it does not; PICTURE COMPLETION and BLOCK DESIGN, measuring figural intelligence; the score on the latter test drops significantly with deterioration, whereas on the former it does not, ${ }^{28}$ DIGIT SPAN, measuring those aspects of short-term memory which are relevant for the criterion tests; the score on this test also drops markedly with mental deterioration. In addition, the Stroop COLOUR-WORD test was used for assessing attentional deficits. ${ }^{29}$

\section{Criterion tests}

WORD PRODUCTION 1 and 2. Subjects were initially asked to mention as many animals names as possible (= word production 1) and, next, to name as many professions as possible within one minute (= word production 2$)$. The scores consisted of the total number of the mentioned items. These tasks are standard subtests in the Groningen Intelligence Test (GIT) and represent "ideational fluency" 30

BLOCK SORTING. The material for this test consisted of 27 blocks differing along three dimensions: form (circle, square, triangle), colour (red, blue, yellow) and size (small, medium, large). Subjects were asked to assign each block to one out of three sample blocks differing from each other in each of the three dimensions (a small yellow circle, a large red triangle and a medium-sized blue square). Initially, the criterion dimension was form. After five correct assignments in succession the experimenter changed the target dimension. The score of this test consisted of the number of trials preceeding five correct successive assignments to the criterion dimension colour. Before the presentation of the blocks the following instructions were given to the subject: "I am going to show you several blocks, one at a time. Each of them matches with one of three sample blocks. You will be asked to indicate with which one this block matches. Then, I will tell you whether your choice is correct", After five correct assignments in succession: 'We are going to start a new series now; you must make a choice again".

ANIMALS SORTING. The material for this consisted of two series of 24 cards; the name of an animal species was printed on each of them in capitals. The task was to assign each card to one out of the two sample cards GOAT and FALCON. Initially, the sorting dimension was bird vs mammal. After seven successive correct assignments the target dimension was changed to domestic vs wild. The score for this test was the total number of trials that the subject needed to discover the latter criterion dimension. The instructions given to the subjects were analogous to those for Blocks Sorting.

MOTOR SEQUENCES D and ND. For these tests, keyboards were constructed with four push-buttons, analogous to the apparatus for the repetitive finger movements task used by Perret, Eggenberger and Siegfried. ${ }^{24}$ Before starting this criterion test, the basic motor ability of the subjects was assessed by measuring the number of pushes given during $15 \mathrm{~s}$; in this case, there was no particular sequence prescribed (spontaneous level of performance or "free sequence"). The tests consisted of two phases. The subject had to press each push-button as frequently as he could during $15 \mathrm{~s}$ in the following sequence: index finger-middle finger-ring finger-little finger (first phase). During a next period of $15 \mathrm{~s}$ the sequence was changed to: index finger-ring finger-middle fingerlittle finger (second phase). The following quantities were computed: $T$, total number of pushes in each phase; $C$, total number of correct successive pushes in each phase (a push was counted as correct when it was preceded or followed by the correct push as defined in the sequence); the ratio $\mathrm{C} / \mathrm{T}$, that is, the proportion of correct pushes. The latter was taken as a measure of the performance in each phase, in order to match subjects with respect to preexisting differences in total amount of responding; consequently, the quality of sequential performance was measured without confounding due to just the number of finger pushes. MOTOR SEQUENCE D had to be performed with the dominant hand. MOTOR SEQUENCE ND had to be performed with the other hand; the apparatus for the latter test was symmetrical to that for the former.

\section{Procedure}

The subjects had to meet certain minimal criteria as to intelligence and motor functioning in order to participate in the study. The lower limit for the WAIS Vocubulary test 
and the WAIS Block Design test was set at a score of 85 . Furthermore, each finger of both hands had to be able to push the corresponding button of the keyboard. The sequence of the criterion tests and of the remaining reference tests was as follows: WORD PRODUCTION 1 and 2, BLOCKS SORTING, Stroop COLOUR-WORD test, WAIS PICTURE COMPLETION, WAIS DIGIT SPAN, ANIMAL SORTING, WAIS SIMILARITIES, and MOTOR SEQUENCES D and ND. The duration of this programme was about three hours, including a break. This amount of time was ensured in order not to press or to stress the patients.

Measurement of "shifting aptitude" and statistical analysis Differences with respect to mean performance on the reference tests for intelligence, short-term memory and attention, as well as the criterion tests for "shifting aptitude" between Parkinson's disease patients and control subjects, were assessed in a two-group multivariate analysis of variance by means of the SPSS-procedure MANOVA. ${ }^{31}$ Mean performance on the various variables was evaluated with a uni-variate $F$ Test.

The dependent variable "shifting aptitude" was measured as follows. The performance on each of the two word production tasks was taken as directly reflecting the ability to generate different members of a particular set, that is, the ability to shift from subset to subset. In the remaining criterion tests "shifting aptitude" was measured by the score for the performance during the second phase which, by definition, followed the first phase. The performance during the first phase (non-shift phase) represented baseline performance; the performance during the second phase (shift phase) by definition represented "shifting aptitude". The "shifting aptitude" score in the sorting tasks was considered to consist of the number of trials needed to detect the change in sorting criterion; analogously, in the motor tasks it was the proportion of correct pushes in the shift phase.

Although the performance during the second phase of each criterion test by definition represented "shifting aptitude", differences between Parkinson's disease patients and control subjects could be partly due to differences in the baseline performance. This confounding source of variation was eliminated by means of analysis of covariance (univariate): the shift phase scores were regressed on the baseline scores. Thus, remaining differences between the two groups could be unequivocally interpreted as the result of differences in "shifting aptitude". In case the statistical analysis indicated that regression of shift phase scores on baseline scores was not parallel for the Parkinson group and the control group (that is, when there was a significant interaction between the presence of Parkinsonism and the covariation between shift and non-shift performance), within-group regression was used instead of the regression pooled across groups. ${ }^{32}$

Two remarks are in order. First, "word production" tests are usually conceived as directly measuring fluency or "shifting aptitude". We prefer this traditional interpretation, because "word production" tests surely tap some form of "shifting aptitude". On the other hand, it could be argued that, by analogy with the other criterion tests, "shifting aptitude" is represented properly by the perfor- mance during the "word production" test, that is, immediately following parallel test that may reflect in addition a kind of higher-order "shifting aptitude". Given these alternatives, two kinds of analyses were performed: a comparison of the mean performance on both word production tests separately, and an analysis of covariance using the outcome of the "word production 2" test as criterion variable and that of the "word production 1" test as a concomitant variable. Second, it should be noted that the analysis of covariance procedure for the motor tests is double conservative. As the dependent variable consists of the proportion of correct pushes in the shift phase, there is already a correction for a a priori differences between Parkinson's disease patients and control subjects with respect to general (or basic) motor abilities. The present study does not focus on motor performance per se, but some pertinent results will be discussed because of the traditional interest in this topic.

\section{Results}

Table 3 summarises the mean scores of the Parkinson group and the control group on the references tests for intelligence, short-term memory and attention. The differences between the group means are not significant. The multivariate F-ratio is $0 \cdot 85$, with df $=6$ and 30 , and $p \leqslant 0 \cdot 54$. So, the Parkinson group and the control group are well-matched with respect to the level of intelligence, short-term memory and attention.

The mean performance of both groups on the criterion tests for "shifting aptitude" is summarized in table 4. Apart from the basic data on cognitive performance, which are shown in the latter table, the basic data on motor performance are shown in table 5. These data are relevant for evaluating the possible contribution of deficits in basic motor performance to the observed deficits in shifting aptitude at the motor level (see Discussion). The mean level of "shifting aptitude" in Parkinson's disease patients is significantly affected. The multivariate F-ratio is 2.29 , with $\mathrm{df}=10$ and 26 , and $p \leqslant 0.43$. The univariate statistics are shown in table 6 . Moreover, the difference with respect to the control group are consistently in the predicted direction of impaired performance. Parkinson's disease patients produced fewer different names of animals and professions

Table 3 Means and standard deviations (in brackets) of the scores on the reference tests for Parkinson patients $(n=18)$ and control subjects $(n=19)$

\begin{tabular}{lllll}
\hline Test & \multicolumn{2}{l}{ Parkinson } & group & \multicolumn{2}{l}{ Control group } \\
\hline Vocabulary & 36.12 & $(9.74)$ & 41.05 & $(9.02)$ \\
Similarities & 16.33 & $(5.34)$ & 17.47 & $(4.17)$ \\
Pictures & 10.50 & $(3.09)$ & 11.37 & $(3.51)$ \\
Block design & 10.67 & $(4.43)$ & 12.16 & $(5 \cdot 19)$ \\
Digit span & 11.78 & $(2.73)$ & 12.32 & $(3.84)$ \\
Colour-word & 58.83 & $(20.70)$ & 49.32 & $(17.00)$ \\
\hline
\end{tabular}


Table 4 Means and standard deviations (in brackets) of the scores on the criterion tests

\begin{tabular}{|c|c|c|c|c|}
\hline$\frac{\text { Test }}{\text { Word production 1 (B) }}$ & \multicolumn{2}{|c|}{ Parkinson group } & \multicolumn{2}{|c|}{ Control group } \\
\hline $\begin{array}{l}\text { Word production } 1 \text { (B) } \\
\text { Word production } 2 \text { (S) } \\
\text { Blocks sorting B } \\
\text { Blocks sorting S } \\
\text { Animals sorting B } \\
\text { Animals sorting S } \\
\text { Motor sequences (D) B } \\
\text { Motor sequences (D) S } \\
\text { Motor sequences (ND) B } \\
\text { Motor sequences (ND) S }\end{array}$ & $\begin{array}{r}17 \cdot 6 \\
12 \cdot 7 \\
2 \cdot 8 \\
21 \cdot 8 \\
3 \cdot 8 \\
13 \cdot 3 \\
63 \cdot 7 \\
54 \cdot 8 \\
57 \cdot 4 \\
52 \cdot 1\end{array}$ & $\begin{array}{l}\left(\begin{array}{l}2 \cdot 3 \\
3 \cdot 2\end{array}\right) \\
5 \cdot 6) \\
4 \cdot 6) \\
5 \cdot 1 \\
9 \cdot 3 \\
(27 \cdot 8) \\
(34 \cdot 0) \\
(30 \cdot 7) \\
(37 \cdot 3)\end{array}$ & $\begin{array}{r}21 \cdot 0 \\
16 \cdot 8 \\
1 \cdot 6 \\
15 \cdot 6 \\
1 \cdot 3 \\
7 \cdot 0 \\
77 \cdot 3 \\
78 \cdot 4 \\
77 \cdot 7 \\
81 \cdot 6\end{array}$ & $\begin{array}{l}\left(\begin{array}{l}4 \cdot 8) \\
4 \cdot 5 \\
1 \cdot 3 \\
8 \cdot 2 \\
0 \cdot 5\end{array}\right) \\
7 \cdot 9 \\
\left(\begin{array}{l}20 \cdot 6 \\
15 \cdot 3 \\
22 \cdot 6 \\
14 \cdot 3\end{array}\right)\end{array}$ \\
\hline
\end{tabular}

$\mathrm{B}=$ baseline data; $\mathrm{S}=$ scores obtained for the shift phase; $\mathrm{D}=$ dominant hand; ND = non-dominant hand

Note that for the word production tests each one in itself can be interpreted as a test for shifting aptitude; alternatively, the first test may be conceived as the B-phase for the second test (S-phase).

Table 5 Basic data for motor performance: means and standard deviations (in brackets)

\begin{tabular}{|c|c|c|c|c|c|}
\hline \multirow[b]{2}{*}{$\begin{array}{l}\text { Free sequence } \\
T_{F} D \\
T_{F} \text { ND }\end{array}$} & \multicolumn{2}{|c|}{ Parkinson group } & \multicolumn{2}{|c|}{ Control group } & \multirow{2}{*}{$\begin{array}{l}p \\
0.002 \\
0.001\end{array}$} \\
\hline & $\begin{array}{l}6 \cdot 0 \\
6 \cdot 0\end{array}$ & $\left(\begin{array}{l}2 \cdot 4) \\
2 \cdot 6)\end{array}\right.$ & $\begin{array}{r}9.7 \\
10.7\end{array}$ & $\left(\begin{array}{l}3 \cdot 8) \\
4 \cdot 7\end{array}\right)$ & \\
\hline $\begin{array}{l}\text { First sequence (B) } \\
T_{1} \text { D } \\
T_{2} \text { ND } \\
C_{1} \text { D } \\
C_{1} \text { ND }\end{array}$ & $\begin{array}{l}27 \cdot 1 \\
26 \cdot 6 \\
18 \cdot 7 \\
14 \cdot 9\end{array}$ & $\begin{array}{r}(11 \cdot 1) \\
(9 \cdot 5) \\
(14 \cdot 0) \\
10 \cdot 1)\end{array}$ & $\begin{array}{l}36 \cdot 3 \\
33 \cdot 9 \\
27 \cdot 7 \\
27 \cdot 0\end{array}$ & 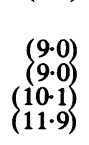 & $\begin{array}{l}0.009 \\
0.02 \\
0.03 \\
0.002\end{array}$ \\
\hline $\begin{array}{l}\text { Second sequence (S) } \\
\mathrm{T}_{2} \mathrm{D} \\
\mathrm{T}_{2} \mathrm{ND} \\
\mathrm{C}_{2} \mathrm{D} \\
\mathrm{C}_{2} \mathrm{ND}\end{array}$ & $\begin{array}{l}20 \cdot 9 \\
20 \cdot 9 \\
11 \cdot 6 \\
10 \cdot 1\end{array}$ & 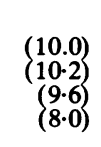 & $\begin{array}{l}24 \cdot 0 \\
23 \cdot 0 \\
19 \cdot 1 \\
19 \cdot 2\end{array}$ & $\left.\begin{array}{l}7 \cdot 1) \\
6 \cdot 8 \\
7 \cdot 9 \\
7 \cdot 8\end{array}\right)$ & $\begin{array}{l}0.29 \\
0.46 \\
0.01 \\
0.001\end{array}$ \\
\hline $\begin{array}{l}\mathrm{C}_{1} \mathrm{~T}_{1} / \mathrm{T}_{\mathrm{F}} \mathrm{D}^{\mathrm{D}} \\
\mathrm{C}_{1} / \mathrm{T}_{\mathrm{F}} / \mathrm{ND} \\
\mathrm{C}_{2} \mathrm{~T}_{2} / \mathrm{T}_{\mathrm{F}} \mathrm{D} \\
\mathrm{C}_{2} \mathrm{~T}_{2} / \mathrm{T}_{\mathrm{F}} \mathrm{ND}\end{array}$ & $\begin{array}{r}114 \cdot 4 \\
81 \cdot 1 \\
53 \cdot 6 \\
43 \cdot 7 \\
\end{array}$ & $\begin{array}{r}(133 \cdot 2) \\
(77 \cdot 4) \\
72 \cdot 3 \\
(40 \cdot 2)\end{array}$ & $\begin{array}{r}127.5 \\
109.9 \\
60.8 \\
53.5\end{array}$ & $\begin{array}{l}(90 \cdot 1) \\
82 \cdot 4) \\
43 \cdot 9 \\
36 \cdot 5)\end{array}$ & $\begin{array}{l}0.73 \\
0.28 \\
0.20 \\
0.20\end{array}$ \\
\hline
\end{tabular}

$T_{F}, T_{1}$ and $T_{2}=$ total number of finger pushes in the free sequence, the baseline sequence and the shift sequence respectively.

$C_{1}$ and $C_{2}=$ total number of correct pushes in the baseling and shift sequence.

$\mathrm{D}=$ dominant hand; ND = non-dominant hand.

The entries in the column headed by $p$ are the probability levels of univariate F-ratio.

Table 6 Statistical analyses of differences in mean performances on the criterion tests between Parkinson patients $(n=18)$ and control subjects $(n=19)$

\begin{tabular}{|c|c|c|c|c|c|}
\hline \multirow[t]{2}{*}{ Criterion test } & \multicolumn{5}{|c|}{ Significance of various statistical tests } \\
\hline & 1 & 2 & 3 & 4 & 5 \\
\hline \multirow{7}{*}{$\begin{array}{l}\text { Word production } 1 \text { (B) } \\
\text { Word production } 2 \text { (S) } \\
\text { Blocks sorting B } \\
\text { Blocks sorting S } \\
\text { Animals sorting B } \\
\text { Animals sorting S } \\
\text { Motor sequences (D) B } \\
\text { Motor sequences (D) S } \\
\text { Motor sequences (ND) B } \\
\text { Motor sequences (ND) S }\end{array}$} & \multirow{7}{*}{$\begin{array}{l}0.009 \\
0.003 \\
0.348 \\
0.008 \\
0.044 \\
0.033 \\
0.099 \\
0.010 \\
0.028 \\
0.003\end{array}$} & 0.034 & 0,044 & 0047 & \multirow{5}{*}{0.022} \\
\hline & & 0.034 & 0.044 & $0.04 \pi$ & \\
\hline & & 0.80 & 0.011 & 0.34 & \\
\hline & & 0.78 & 0.04 & 0.64 & \\
\hline & & & & & \\
\hline & & 0.000 & 0.045 & 0.035 & 0.009 \\
\hline & & 0.000 & 0.047 & 0.01 & 0.002 \\
\hline
\end{tabular}

1 = univarate analysis of variance for group differences (F-ratio)

$2=$ regression of shift-phase scores on baseline scores

$3=$ univariate analysis of variance for group differences after elimination of pooled regression

$4=$ test for regression parallellism

$5=$ significance of group differences after elimination of within-group regression

Entries are probability levels. 
Table 7 Correlations between the reference tests

\begin{tabular}{lrrrrrl}
\hline & $V$ & \multicolumn{1}{l}{$S$} & \multicolumn{1}{l}{$P$} & \multicolumn{1}{l}{$B$} & \multicolumn{1}{l}{$D$} & \multicolumn{1}{l}{$C$} \\
\hline V & - & 0.56 & 0.54 & 0.43 & 0.58 & -0.07 \\
S & 0.82 & - & 0.73 & 0.64 & 0.78 & -0.30 \\
P & 0.10 & 0.13 & - & 0.72 & 0.48 & -0.37 \\
B & 0.01 & 0.15 & 0.75 & - & 0.42 & -0.05 \\
D & 0.13 & -0.17 & 0.22 & 0.12 & - & -0.20 \\
C & -0.29 & -0.31 & -0.18 & -0.27 & -0.45 & - \\
\hline
\end{tabular}

Lower triangular part: Parkinson group

Upper triangular part:Control group

$$
\begin{aligned}
& V=\text { vocubulary } B=\text { block design } \\
& S=\text { similarities } D=\text { digit span } \\
& P=\text { pictures } \quad C=\text { colour-word }
\end{aligned}
$$

Mean correlation of V, S, P, B $=0.60$ (control group)

Mean correlation of V, S, P, B $=\mathbf{0 . 3 2}$ (Parkinson group)

respectively than control subjects did; they needed more trials for detecting a shift in the criterion for sorting blocks and animals respectively; and they produced a smaller proportion of correct finger responses in a changed pushing sequence than control subjects did.

The effects of Parkinsonism are not confined to a decrease in mean level of performance on the criterion tests. The overall pattern of relationships between the various tests, as contained in the variance-covariance matrices for both groups, was also significantly different not only for the criterion variables but also for the reference variables. Box's M-statistic for testing the homogeneity of the variance-covariance matrices for the reference tests is 43.14; the associated F-transformation is 1.67 , with df $=21$ and 4474 , and $p \leqslant 0.028$. For the scores from the shift phases of the criterion tests, the corresponding values are $\mathrm{M}=35, \mathrm{~F}=1.07$ (with $\mathrm{df}$ $=15$ and 4897) and $p \leqslant 0.013$. Although homogenous variance-covariance matrices are formally required when mean differences are to be tested with an F-test, it has been shown that this test is rather robust against heteroscedasticity (and against non-normality), particularly in the case of two groups with an equal number of subjects. ${ }^{33}$ The

Table 8 Correlations between the scores for the shift phases of the criterion tests

\begin{tabular}{lllllr}
\hline & WP2 & \multicolumn{1}{c}{$B S$} & \multicolumn{1}{c}{ AS } & PCD & \multicolumn{1}{c}{ PCND } \\
\hline WP2 & - & -0.18 & -0.34 & 0.07 & 0.33 \\
BS & -0.12 & - & -0.23 & 0.15 & -0.36 \\
AS & -0.26 & 0.31 & - & -0.10 & -0.00 \\
PCD & 0.24 & -0.26 & -0.30 & - & 0.42 \\
PCND & 0.28 & -0.16 & -0.16 & 0.78 & - \\
\hline
\end{tabular}

Lower triangular part: Parkinson group

Upper triangular part:Control group

WP2 = word production 2

$\mathrm{BS}$ = block sorting

AS = animal sorting

PCD percentage of correct pushes (dominant hand)

PCND percentage of correct pushes (non-dominant hand) significant difference in covariance structure, however, is a remarkable finding in its own right, and merits further investigation. For the time being, inspection of the within-group correlation matrices may serve as a substitute. The correlation matrix for the reference tests is given in table 7 , whereas the matrix for the criterion tests is shown in table 8 (for $\mathrm{n}=18$ and $\alpha=0.05$ the critical value for a single $\mathrm{r}$ is 0.47 ; for $\mathrm{n}=19$ and $\alpha 0.05$ it is 0.46 . When correlations between five variables are to be assessed simultaneously, the critical values are 0.66 and 0.63 respectively). The mean correlation between the reference variables representing intelligence is in agreement with data from the literature $(0 \cdot 60) ; 27$ it is on average lower in the Parkinson's disease group than in the control group $(0 \cdot 32$ vs $0 \cdot 60)$. The general intelligence structure in subjects with Parkinson's disease tends to dissociate, although the mean level of intelligence remains normal; the various intelligence factors lose their normal association pattern. At the same time, the significant decrease in the level of "shifting aptitude" appears to strengthen the association between the various tests which were used to measure the construct. It is precisely this common factor in the test that is affected in Parkinson subjects: the tests converge in their common fate of impairment. Additional evidence for group differences in the structural relationships within the set of criterion tests is provided by the fact that the regression of shift phase scores on baseline scores of word production 2 and motor sequences $\mathrm{D}$ and ND, is not parallel for the Parkinson group and the control group (table 6).

\section{Discussion}

The results of the present study appear to confirm the hypotheses that " shifting aptitude" is decreased in patients with an impaired functioning of the basal ganglia, and that this diminished "shifting aptitude" manifests itself at several levels of behaviour organisations, that is, the cognitive and motor level.

DEFICITS AT THE MOTOR LEVEL

Regarding the deficits in the motor performance (tables 4, 5, and 6) "shifting aptitude" is significantly diminished in Parkinson's disease patients; this deterioration cannot be due to basic motor deficits. The latter would affect performance in both the baseline phase and the shift phase. Because variation due to baseline performance was removed from variation in the shift phase (table 6 , column 2), any common factor affecting both phases was eliminated effectively from "shifting aptitude" scores (table 6, column 5). Therefore, whatever (motor) deficits affect motor performance during 
the baseline phase, these were not responsible for (residual) differences in "shifting aptitude" between Parkinson's disease patients and control subjects. (The question of correlation between laterality of the major Parkinson symptoms and hemispheric dominance on the one hand, and asymmetry of the deficient "shifting aptitude" on the other hand cannot be answered because of the relatively small number of patients per subgroup (cf. ref. 9).

Discussion of the experimental results requires a clear distinction between three components of the performance: (1) the capacity for executing finger movements, (2) the capacity for executing serial movements in a fixed sequence, and (3) the capacity for executing shifts in set from one fixed sequence of movements to another, that is "shifting aptitude" that manifests itself in the motor modality.

(1) As to the first component, Parkinson's disease patients generally differ from control subjects with respect to basic motor performance such as muscular weakness, rigidity and other factors reducing the capacity for executing movements. This was indeed the case in the present study. There was a significant difference between the Parkinson's disease patients and the control subjects when they had to press each of the push-buttons without a prescribed sequence (free sequence); as shown in table 5 , the group means were $6.0( \pm 2.4)$ vs $9.7( \pm 3.8)$ with $p \leqslant 0.002$ (dominant hand) and 6.0 $( \pm 2.6)$ vs $10.7( \pm 4.7)$ with $p \leqslant 0.001$ (non-dominant hand). Still, the differences in indices for "shifting aptitude" cannot be ascribed to these impairments: the actual number of correct successive button-pushes was expressed in relation to the total number of pushes, thereby correcting possible differences in this respect. Moreover, the relevance of this component is weakened both by the selection procedure, that is, eliminating patients who were clearly unable to execute the required finger movements, and by the fact that the Hoehn-Yahr score of the patients was well below the maximum of 5: the ratings varied from 1 to 4 with a mean of $2 \cdot 4 \pm 0 \cdot 8$.

(2) As to the second component, Parkinson's disease patients may have difficulties in executing serial movements in a fixed sequence. ${ }^{24}$ A score for this capacity was defined as the product of the total number of pushes in the first sequence and the number of correct pushes in that phase divided by the number of pushes in the free sequence, that is a score for executing serial movements corrected for initial differences in the capacity for executing finger movements per se (table 5). The PD group did not significantly differ from the control group on this measure: $114.4( \pm 133 \cdot 2)$ vs $127 \cdot 5( \pm 90 \cdot 1)$ with $p \leqslant$ 0.73 (dominant hand) and $81.1( \pm 77.4)$ vs 109.9 $( \pm 82.4)$ with $p \leqslant 0.28$ (non-dominant hand). This holds also true for the second sequence: 53.6 $( \pm 72.3)$ vs $60.8( \pm 43.9)$ with $p \leqslant 0.20$ (dominant hand) and $43.7( \pm 0.2)$ vs $53.5( \pm 36.5)$ with $p \leqslant$ $0 \cdot 20)$ (non-dominant hand) (table 5 ). This outcome is not in agreement with previous studies showing that Parkinson's disease patients have difficulties in a simple serial motor task." ${ }^{24}$ Three factors may have contributed to this discrepancy: (a) The degree of pathology of the patients; in the present study patients with an average Hoehn-Yahr rating score of $2.4( \pm 0 \cdot 8)$ were tested. If the degree of pathology is indeed a crucial factor, the present study may imply that patients with a relatively low Hoehn-Yahr rating score do not yet show the impairment found by Perret et al. ${ }^{24}$ (b) The influence of muscular weakenss, rigidity and other factors which reduce the capacity for executing movements; in contrast to the index used in previous studies, the index in the present study was corrected for these factors (see above). If these factors are indeed of crucial importance, the present study may imply that Parkinson's disease patients have no central programming deficit regarding the execution of fixed sequences of fingers (cf. refs. 23-25). (c) The influence of drug therapy; in contrast to patients in previous studies, the patients in the present study received a treatment with various antiparkinsonian agents. If the drug treatment is indeed a crucial factor, the present study may imply that antiparkinsonian agents can ameliorate the impairment under discussion (cf. ref. 11)

At the moment it is not yet possible to elucidate which factor underlines the demonstrated absence of any significant impairment in executing serial movements in a fixed sequence of finger movements.

(3) Returning to the scores for "shifting aptitude", the data demonstrate that Parkinson's disease patients have a significant reduction in capacity for executing shifts in set from one fixed sequence of movements to another, that is, a diminished "shifting aptitude". Neither a reduction in the capacity of executing movements per se, nor a reduction in capacity for executing serial movements in a fixed sequence, sufficiently accounts for the deficit found. Moreover, although the second sequence turned out to be more difficult than the first one (table 5: $C_{1} T_{1} / T_{f}$ vs $C_{2} T_{2} / T_{f}$ ) the significant difference in the proportion of correct pushes in the second sequence, that is, the shifting aptitude score, is not likely to be caused by that factor because the overall performance of the Parkinson's disease patients in the second sequence did not differ significantly from that of control subjects (table 5 : $C_{2} T_{2} / T_{f}$ for $P D$ vs $C_{2} T_{2} / T_{f}$ for controls).

Since triggering, monitoring or adjusting ongoing movements by currently available sensory informa- 
tion (except from memorised tactile cues being connected with proprioceptive information) was impossible in the chosen set-up, the present study allows the conclusion that the diminished "shifting aptitude" is manifest in motor behaviour that is triggered and guided by self-generated information (cf. "open loop" (feed-forward or anticipatory) behaviour; cf. ballistic movements). This conclusion fits in with Stark's contention 22 that Parkinson's disease patients have lost their ability to control voluntary "open loop" movements; it also fits in with Flowers' idea $^{21}$ that these patients lack a dynamic "internal model" of their own movements from which to control them predictively. As a final remark in this context, a diminished "shifting aptitude" in the motor modality offers an explanation for the earlier finding that Parkinson's disease patients have problems in planning or anticipating motor behaviour; ${ }^{21}$ for, the latter is simply the consequence of the former.

\section{DEFICITS AT THE COGNITIVE LEVEL}

Regarding the deficits seen in the cognitive tests, table 6 clearly shows that there are significant differences between the two groups with respect to the criterion tests for "shifting aptitude" in the verbal and figural modality. First, word production tests: regarding the two alternative kinds of interpretations (see Methods, measurement of "shifting aptitude" and statistical analysis), table 6 shows that there are significant differences between the Parkinson and control group in both cases: table 6 , column 1 (traditional interpretation) and table 6 , column 5 (alternative interpretation, starting from the point of view that "word production 2" test reflects, in addition, a kind of higher-order "shifting aptitude"); as the regression of the shift phase scores on baseline scores was not parallel in the latter case (table 6 , column 4) within-group regression was used for the statistical analysis (table 6, column 5). And, next, the sorting of animals and professions respectively: given the parallelism in these tests (table 6, column 4 ), the regression pooled across groups was used for the statistical analysis (table 5, column 3 ). The differences in baseline performance on the animals sorting test are not relevant for the "shifting aptitude" deficits; moreover, these differences have been corrected for by means of the covariance analysis. Finally, the other tests do not suggest the presence of deficits in concept formation (baseline performance for Blocks and Similarities). No significant differences were found in the reference tests (table 3). Lastly, it seems justified to refute any significant contribution of the anti-parkinson therapy to the deficit under discussion, because there was no significant difference between the Par- kinson's disease patients and the control subjects in any neuropsychological measure which might be affected by these agents: table 3, five subtests of the WAIS. ${ }^{34}$ Nevertheless, assessment of the same kind of "shifting aptitude" analysis in de novo patients can offer important information in this respect.

Several investigators have found that Parkinson's disease patients after some time demonstrate a general cognitive deterioration and (or) dementia. ${ }^{1235-39}$ This accelerated decline in the functioning of cognition and thought is sometimes suggested to be related to cortical damage (cf. ref. 15). In the present study, however, the latter factor was controlled with the help of reference tests for general mental deterioration. Because there was no difference between Parkinson's disease patients and control subjects in these tests, the demonstrated decrease in "shifting aptitude" cannot be due to a decrease in intelligence. It should be noted that the present results do not contradict the occurrence of intellectual deterioration in Parkinson's disease patients, because the matching procedure by design established groups of comparable intelligence without any reference to age- or education-related norms. It is only shown that differences in "shifting aptitude" cannot be related to intelligence, as this factor was held constant. Nevertheless, it remains an interesting finding that the structure of intelligence of Parkinson's disease patients is dissociated (see table 6). They did not have lower scores than the control subjects, but the association between the scores changes in the direction of decrease (verbal vs figural) as well as increase (vocabulary vs similarities). We do not yet have an explanation for this phenomenon. It may be possible that in Parkinson's disease patients hemispheric specialisation progresses at the cost of hemispheric integration, as Bentin has pointed out. ${ }^{40}$

Barbeau $^{14}$ also states that Parkinson's disease patients with a normal memory and intelligence are relatively incapable " to shift to a new grouping". He interprets this as an impairment in the strategy of learning. This interpretation fails to explain the differences found in word production (table 6), a task that does not call for learning strategies. Nevertheless, the outcome of the present study is in agreement with Barbeau's statement that, once a repetitive pattern has been established, the Parkinson's disease patient has primarily difficulty in changing the pattern. This idea contradicts that of Bowen ${ }^{9}$ who asserts that Parkinson's disease patients have difficulty with shifting as well as maintaining a set. The patients in the present study did not show any substantial impairment in the digit span test and colour-word test, that is, tests which are typically assessing set-maintaining capacities (table 3 ). 
The results of the present study do not support the interpretation of Bowen ${ }^{9}$ and Matthews and Haaland,$^{36}$ who view the cognitive deficit of Parkinson's disease patients as an impairment in concept formation. If the production of categorical concepts was actually impaired, the scores of WAIS Similarities test should have been lower in Parkinson's disease patients than in control subjects. In view of the comparable performance on this test (table 3 ), it seems more likely that the Wisconsin Card Test used by Bowen" measures "shifting aptitude" rather than concept formation.

Several studies have revealed a decrease of comparable cognitive deficits in frontal syndromes. ${ }^{4142}$ However, it is unlikely that the defects found in the Parkinson's disease patients may be attributed by dysfunctional frontal lobes. First, this study is conceptualised in analogy with animal experiments with selective manipulations of the basal ganglia (see below). Second, neurological screening of the Parkinson's disease patients did not reveal any symptom of the frontal syndrome. Third, EEG and CT scanning of the Parkinson's disease group did not reveal any frontal lesion such as atrophia. Fourth, there was no difference between Parkinson's disease patients and control subjects on two of the reference tests that are known as measuring frontal functioning, that is, digit span and Stroop colour-word test. ${ }^{28}$ In sum, although frontal functioning is not entirely excluded it is nevertheless unlikely. Possibly further study of cortico-striatal connections may provide a new outlook.

\section{GENERAL}

In sum, evidence is provided that Parkinson's disease patients have a diminished "shifting aptitude" that manifests itself in verbal, figural and motor modalities. It has been established recently that these patients also have a diminished "shifting aptitude" that is manifested in linguistic modality. ${ }^{43}$ These two observations suggest that this deficit is indeed a characteristic feature of Parkinson impairment in programming motor and cognitive functioning. The question whether manifestations of this deficit in modalities with decreasing degrees of complexity are positively correlated with increasing degrees of severity of Parkinsonian symptoms in clinical terms (see: Introduction) cannot be answered here, because of the relatively small differences between the patients investigated (HoehnYahr rating scores, mean $\pm S D=2 \cdot 4 \pm 0 \cdot 8$ ).

Finally, it may be noted that the demonstrated impairment in "shifting aptitude" is fully predicted on the basis of changes in behaviour organisation found in animals with dysfunctioning basal ganglia. ${ }^{1-3616-1844}$ In animals, the basal gang- lia-especially the striatal system-have been found to enable the organism to rearrange arbitrarily the serial order of elements of behaviour programmes. ${ }^{2}$ An increased striatal activity has been found to dissociate behaviour programmes, rendering rearrangement of the resulting elements possible. ${ }^{126} \mathrm{It}$ has been found to improve the animal's ability to shift from one element to another with the help of self-generated information (cf. "open loop" (feedforward or anticipatory) movements; cf. ballistic movements). ${ }^{12}$ A decreased striatal activity has been found to prevent such a dissociation and to bar rearrangement. ${ }^{26}$ However, the animal remains able to rearrange behaviour programmes with the help of currently available sensory information (cf. "closed loop" (feed-back) behaviour; cf. ramp movements). ${ }^{2}$ In animals, consequences of changes in the striatal activity have been found to manifest themselves at different levels of the hierarchy of behaviour organization..$^{218}$ And, finally, pathological changes in the composition of behaviour programmes at hierarchically lower levels have been found to require more change of the striatal activity than do analogous effects at hierarchically higher levels. ${ }^{12644}$ On the basis of these animal data it has become possible to formulate the mentioned hypotheses as to the (dys) functioning basal ganglia of man.

This notion of the actual analogy of the deficits in animals and in man with abnormal function of the basal ganglia has several far-reaching implications; some of them are mentioned below.

First, it underlines the validity of the animal models used to develop an adequate frame of reference for detecting the deficits in human beings. From this point of view, it is relevant to emphasise that, in contrast to classic animal models, the ones selected here analyse brain dysfunctioning in terms of deficits in programming behaviour rather than in terms of deficits in symptomatology.

Second, the actual analogy of deficits in animals and in man with dysfunctioning basal ganglia gives strong support to the hypothesis that the demonstrated impairments have indeed their origin in the basal ganglia of the patients investigated: for, the deficits found in animals were produced by highly selective manipulations within the basal ganglia. ${ }^{1644}$ Accordingly, the evidence presented here favours the view that the basal ganglia are concerned with programming motor and cognitive behaviour. As a final remark, the present evidence does not exclude the possibility that patients with dysfunctioning frontal lobes may have similar deficits. ${ }^{45}$

Thanks are due to $\mathrm{J}$ Hulshof and $\mathrm{B}$ te Molder for taking part in this study. 


\section{References}

${ }^{1}$ Cools AR. Role of neostriatal dopaminergic activity in sequencing and selecting behavioural strategies: facilitation of processes involved in selecting the best strategy in a stressful situation. Behav Brain Res 1980;1:361-78.

${ }^{2}$ Cools AR. Physiological significance of the striatal system: new light on an old concept. In: Szentágothia J, Harnori $\mathrm{J}$ and Palkovits $\mathrm{M}$, eds. Advances in Physiological Sciences, Vol. 2: Regulatory Mechanisms of the CNS Subsystems. Budapest: Akademiai Kiado, 1981;227-30.

${ }^{3}$ Cools AR, Van den Barcken JHL. Cerebral organization of behaviour and the neostriatal function. In: Cools AR, Lohman AHM and Van den Bercken JHL, eds. Psychobiology of the Striatum. Amsterdam: Elsevier/North-Holland Publishing Comp., 1977;119-40.

${ }^{4}$ Divac I, Oberg RGE. The Neostriatum. Oxford: Pergamon Press, 1979.

${ }^{5}$ Kornhuber MH. Cortical and subcortical mechanisms in voluntary movements. In: Chivers DJ and Herbert J, eds. Recent Advances in Primatology, Vol. 1. New York: Academic Press, 1978;635-41.

- Van den Bercken JHL, Cools AR. Evidence for a role of the caudate nucleus in the sequential organization of behaviour. Behav Brain Res 1982;4:319-37.

7 Villablanca JR, Marcus RJ. The basal ganglia. A brief review and interpretation. Acta Neurol Latinoam 1975;21:157-83.

${ }^{8}$ Beardsley JV, Puletti F. Personality (MMPI) and cognitive (WAIS) changes after levodopa treatment. Arch Neurol 1971;25:145-50.

${ }^{9}$ Bowen FP. Behavioural alterations in patients with basal ganglia lesions. In: Yahr MD, ed. The Basal Ganglia. New York: Raven Press, 1976;169-80.

${ }^{10}$ Riklan M. Levodopa and behaviour. Neurology (Minneap) 1972;22 (suppl.):43-54.

"Klaiber R, Siegried J, Ziegler WH, Perret E. Psychomotor effects of L-DOPA combined with a decarboxylase inhibitor on Parkinson patients. Eur $J$ Clin Pharmacol 1971;3:172-5.

${ }^{12}$ Loranger AW, Goodell H, McDowell FH, Lee JE, Sweet RD. Intellectual impairment in Parkinson's syndrome. Brain 1972;95:405-12.

${ }^{13}$ Mettler F, Crandell A. Relation between Parkinsonism and psychiatric disorder. J Nerv Ment Dis 1959; 129:551-63.

14 Barbeau A. Biology of the striatum. In: Gall GE, ed. Biology and Brain Dysfunction, Vol. 2. New York: Plenum Press, 1973;333-50.

15 Marsden CD. The enigma of the basal ganglia and movement. Trends in Neurosciences 1980; November:284-7.

${ }^{16}$ Cools AR. The Caudate Nucleus and Neurochemical Control of Behaviour. Nijmegen: Brakkenstein Press, 1973.

${ }^{17}$ Cools AR. An integrated theory of the aetiology of schizophrenia. In: Van Praag HM, ed. The Origin of Schizophrenic Psychoses. Amsterdam: De Erven Bohn BV, 1975;55-80.
${ }^{18}$ Cools AR. Aspects and prospects of the concept of neurochemical and cerebral organization of aggression: introduction of new research strategies in "Brain and Behaviour" studies. In: Brain PF and Benton D, eds. The Biology of Aggression. Alphen a/d Rijn: Sijthoff \& Noordhoff, 1981;405-25.

19 Flowers K. Visual "closed-loop" and "open-loop" characteristics of voluntary movements in patients with Parkinsonism and intention tremor. Brain 1976;99:269-310.

${ }^{20}$ Flowers K. Some frequence response characteristics of Parkinsonism on pursuit tracking. Brain 1978;101:19-34.

${ }^{21}$ Flowers K. Lack of prediction in the motor behaviour of Parkinsonism. Brain 1978;101:35-52.

${ }^{22}$ Stark L. Neurological Control Systems. New York: Plenum Press, 1968;338-47.

${ }^{23}$ Horne DJ de L. Performance on delayed response tasks by patients with Parkinsonism. J Neurol N'eurosurg Psychiatry 1971;36:742-6.

${ }^{24}$ Perret E, Eggenberger E, Siegfried J. Simple and complex finger movement performance of patients with Parkinsonism before and after a unilateral stereotaxic thalamotomy. J Neurol Neurosurg Psychiatry 1970;33:16-21.

${ }^{25}$ Talland GA, Schwab RS. Performance with multiple sets in Parkinson's disease. Neuropsychologia 1964;2:45-53.

${ }^{26}$ Hoehn MM, Yahr MD. Parkinsonism: onset, progression and mortality. Neurology (Minneap) 1967;17:427-42.

${ }^{27}$ Wechsler D. Manual for the Wechsler Adult Intelligence Scale. New York: Psychological Corporation, 1956.

${ }^{28}$ Golden CJ. Diagnosis and Rehabilitation in Clinical Neuropsychology. Springfield, Ill.: Thomas, 1978.

29 Jensen AR, Rowler WD. The Stroop Color-word test: a review. Acta Psychol 1966;25:36-93.

${ }^{30}$ Ekstrom RB, French JW, Harman HH. Manual for Kit of Factor-referenced Cognitive Tests. Princeton, New Jersey: Education Testing Services, 1976.

${ }^{31}$ Hull CH, Nie NH. SPSS Update 7-9. New York: McGrawhill Book Comp., 1981;1-79.

${ }^{32}$ Maxwell S, Cramer E. A note on analysis of covariance. Psychol Bull 1975;82187-90.

${ }^{33}$ Ito PK. Robustness of ANOVA and MANOVA test procedures. In: Krishnaiah PR, ed. Handbook of Statistics 1. Amsterdam: North-Holland Publ. Comp., 1980;199-236.

${ }^{34}$ Portin R, Rinne UK. Neuropsychological responses of parkinsonism patients to long-term levodopa treatment. In: Rinne UK, Klinger $M$ and Stamm G, eds. Parkinson's Disease. Amsterdam: Elsevier Publ. Comp., 1980.

${ }^{35}$ Hakim AM, Mathison G. Dementia in Parkinsonism disease: a neuropsychological study. Neurology (Minneap) 1979;29:1209-14.

${ }^{36}$ Matthews CG, Haaland KY. The effect of symptom duration on cognitive and motor performance in Parkinsonism. Neurology (Minneap) 1979;29:951-6.

${ }^{37}$ Reitan RM, Boll TJ. Intellectual and cognitive functions in Parkinson's disease. J Cons Clin Psychol 1971;37:364-9. 
${ }^{38}$ Schneider E, Fischer PA, Jacobi P, Becker H, Hacker H. The significance of cerebral atrophy for the symptomatology of Parkinson's disease. J Neurol Sci 1979;42:187-97.

${ }^{39}$ Sweet RD, McDowell FH, Feigenson JS, Loranger AW. Goodell AW. Mental symptoms in Parkinson's disease during chronic treatment with levodopa. Neurology (Minneap) 1976;36:305-10.

${ }^{40}$ Bentin S, Silverberg R, Gordon HW. An asymmetrical cognitive deterioration in demented and Parkinson patients. Cortex 1981;17:533-44.

${ }^{41}$ Milner B. Some effects of rontal lobectomy in man. In: Warren JM and Akert K., Eds. The Frontal Granular
Cortex and Behaviour. New York: McGrawhill, 1964.

42 Nelson HE. A modified card sorting test sensitive to frontal lobe defects. Cortex 1976;12:313-24.

${ }^{43}$ Matison R, Mayeux R, Rosen J, Fahn S. "Tip-of-thetongue" phenomenon in Parkinson's disease. Neurology (NY) 1982;32:567-70.

44 Van den Bercken JHL. Information-statistical Analysis of Social Interation in Java-monkeys, applied in the Neureothology of the Caudate Nucleus. Meppel: Krips Repro BV, 1979.

${ }^{45}$ Barbizet J. Rôle du lobe frontal dans les conduites mnésiques. Presse Med 1971;79:2033-7. 